\title{
Updated S2K AWMF Guideline for the Diagnosis and Follow-up of Obstructive Sialadenitis - Relevance for Radiologic Imaging
}

\section{Aktualisierte S2k AWMF Leitlinie zur Diagnostik und Therapiekontrolle der Obstruktiven Sialadenitis - Bedeutung für die Radiologische Diagnostik}

Authors

Affiliations
T. J. Vogl', B. Al-Nawas² ${ }^{2}$ D. Beutner ${ }^{3}$, U. Geisthoff ${ }^{4}$, O. Gutinas-Lichius ${ }^{5}$, C. Naujoks ${ }^{6}$, R. Reich ${ }^{7}$, U. Schröder ${ }^{8}$, C. Sproll ${ }^{6}$, A. Teymoortash ${ }^{9}$, J. Ußmüller ${ }^{10}$, C. Wittekindt ${ }^{9}$, J. Zenk ${ }^{11}$, S. Fischer ${ }^{1}$

Affiliation addresses are listed at the end of the article.
Key words

- head/neck

salivary glands

- ultrasound received $\quad 7.5 .2014$

accepted $\quad 16.6 .2014$

\section{Bibliography}

DOI http://dx.doi.org/

10.1055/s-0034-1366867

Published online: 2014

Fortschr Röntgenstr 2014; 186 :

843-846 @ Georg Thieme

Verlag KG Stuttgart · New York .

ISSN 1438-9029

\section{Correspondence}

\section{Prof. Thomas J. Vogl}

Institut für Diagnostische und Interventionelle Radiologie,

J. W. Goethe-Universität

Frankfurt

Theodor-Stern Kai 7

60596 Frankfurt

Germany

Tel.: ++49/69/63017277

Fax: ++ 49/69/63017258

T.vogl@em.uni-frankfurt.de

\section{Abstract \\ $\nabla$}

The interdisciplinarily developed German S2k AWMF guideline for the treatment of obstructive sialadenitis represents a new standard in the guideline program of the AWMF, the German Society for Consultants and the clinical disciplines working in the field of diseases of the head and neck region. In the last few years new diagnostic and therapeutic possibilities have been established in obstructive chronic Sialadenitis offering individually optimized therapeutic strategies. Only a few years ago extirpation of the whole affected gland was the only relevant therapy option. Nowadays therapeutic options such as interventional sialendoscopy and extracorporeal shock-wave lithotripsy (ESWL) are available in combination with marsupialization or incision of the duct. If possible the focus is on preserving the main glandular duct. In the following article the relevant aspects for the diagnostic radiologic procedures are presented.

Key Points:

- Radiological methods are a noninvasive alternative to sialendoscopy and should be given preference in the case of acute inflammation.

- Sonography is the radiological method of first choice.

- The use of intravenous or intraductal contrast agent is not necessary due to the prestenotically dilated duct system.

\section{Citation Format:}

- Vogl TJ, Al-Nawas B, Beutner D et al. Updated S2K AWMF Guideline for the Diagnosis and Follow-up of Obstructive Sialadenitis Relevance for Radiologic Imaging. Fortschr Röntgenstr 2014; 186: 843-846

\section{Zusammenfassung \\ $\nabla$}

Die interdisziplinär erarbeitete deutsche $\mathrm{S} 2 \mathrm{k}$ AWMF Leitlinie zur Behandlung der obstruktiven Sialadenitis stellt einen neuen Stand im Rahmen des Leitlinienprogrammes der AWMF, der deutschen Facharztgesellschaft und den klinischen Disziplinen dar, die mit Erkrankungen der Kopf-HalsRegion befasst sind. Die obstruktive chronische Sialadenitis hat in den letzten Jahren Erneuerungen bezüglich ihrer Diagnostik und auch der therapeutischen Möglichkeiten erfahren. So kann heute durch eine verbesserte radiologische Diagnostik eine individuell optimierte Therapie durchgeführt werden. Noch vor wenigen Jahren war die Exstirpation der gesamten betroffenen Drüse die einzige relevante Therapieoption. Heute liegen Verfahren vor wie die interventionelle Sialendoskopie oder die extrakorporale Stoßwellenlithotripsie in Kombination mit einer Gangschlitzung oder Gangmarsupialisation. Die erstrebenswerte Rekanalisation des Hauptganges der Drüse steht dabei im Vordergrund. Im Folgenden sollen die für die Radiologie relevanten Aspekte vorgestellt werden.

\section{Introduction \\ $\nabla$}

There are six large extraoral salivary glands including two parotid glands, two submandibular glands, and two sublingual glands. Obstructive sialadenitis refers to inflammation of these glands caused by an obstruction of the excretory duct. Obstructive sialadenitis is characterized by reduced or absent saliva excretion of the affected gland with a subsequent bacterial superinfection. Absolute saliva production is not affected. The symptoms of obstructive sialadenitis are characterized by recurrent, periprandial swelling of the gland which is often painful and lasts for hours to days. 
The main cause in $60-70 \%$ of cases is obstructive sialolithiasis which is usually unilaterally symptomatic. The prevalence is approximately $1 \%$. It occurs primarily between the ages of 40 and 60 [1]. Sialolithiasis with synchronous obstruction of two salivary glands occurs in less than $3 \%$ of cases and is considered an anatomical exception when the excretory duct of the sublingual gland as a normal variation empties exclusively into the Wharton's duct [2].

The main causes of non-stone-based obstructive diseases are stenoses or strictures which occur synchronously with greater frequency. This can also be caused by etiologically largely unclarified sialadenitis as primary inflammation of the duct epithelium as well as radioiodine therapy. A mechanical obstruction, for example caused by extraductal compression of a tumor, is also possible. In contrast, cases of non-obstructive sialadenitis, such as juvenile sialadenitis or autoimmune sialadenitis in Sjögren's syndrome, should be differentiated.

\section{Method \\ $\nabla$}

The updated S2K guideline describes all currently relevant diagnostic and therapeutic methods for treating obstructive sialadenitis. The guideline was created under the auspices of the German Society of Otorhinolaryngology, Head and Neck Surgery and the associated societies such as the German Radiological Society, the German Society of Dental Oral and Craniomandibular Sciences, and the German Society of Otolaryngologists and is based on the elaborated AWMF rules for guideline development [3]. The method is explicitly described in the guideline report which is published on the AWMF homepage together with the guideline (www.awmf.org/leitlinien/detail/II/017-025.html). A group of experts including 14 members who met once for consensus building and related discussions was involved in the creation of the guideline. The contents of the currently expired guidelines "salivary gland infection" and "sialolithiasis" and the valid guideline "salivary glands: hyperadenosis" were included.

\section{Imaging methods}

$\nabla$

Sonography, conventional X-ray sialography, DSA sialography, MR sialography, sialendoscopy, and salivary gland scintigraphy are the main imaging methods. The current guideline provides only one consensus-based recommendation regarding modality selection for diagnosis and recommends sonography as the method of choice. The selection of further diagnostic methods should be made individually based on the particular method limitations and the advantages and disadvantages.

Accurate diagnosis of lithiasis in relation to number, position, size, configuration, and possible fixation of concretions is decisive for the later selection of the suitable treatment method. A detailed classification for concretions and stenoses of the excretory ducts was described in 2011 by Marchal et al. [4].

\section{Sialendoscopy}

Salivary duct endoscopy mentioned here for the sake of completeness is used in otolaryngology and provides highresolution imaging as well as the option of simultaneous intervention under guidance and therefore has found broad acceptance. Acute inflammation is a relative contraindication for sialendoscopy and conventional X-ray sialography due to the increased risk of perforation and bacterial spread. The following only discusses radiologically relevant imaging methods.

\section{Sonography}

Sonography using a 7.5 - 13 MHz linear probe is the method of choice and provides significant diagnostic value due to its high availability, cost efficiency, and ability to be implemented in cases of acute inflammation. It is also suitable for follow-up. As a result of the superficial position of salivary glands, gland architecture and duct systems can be evaluated on B-mode images. The high spatial resolution makes it possible to detect mineralized concretions with a diameter of greater than $1 \mathrm{~mm}$ as well as post-inflammatory duct system changes that can be characterized by changes in impedance [5]. Better differentiation of infiltrating processes and tumorous masses can be achieved via contrast agent enhancement or tomographic imaging [6]. Sonography visualizes abscess formations as hypoechoic, intraglandular masses. Lymph nodes can be a possible differential diagnosis in this case. Sonography makes it possible to detect typical prestenotic duct dilation during functional provocation tests with ascorbic acid, for example [7]. However, the deep portion of the parotid gland can only be evaluated on a limited basis with sonography due to the greater distance from the probe. Finally, in the case of a negative finding, sonography cannot conclusively rule out lithiasis. In this regard, supplementary MRI or CT diagnostic methods can be used for evaluation.

\section{MR sialography}

Highly T2-weighted sequences using the gradient echo technique, single-shot technique, or fast spin echo technique are used for MR sialography. $3 \mathrm{D}$ methods are superior for detecting stenoses and strictures [8] ( $\bullet$ Fig. 1). The use of intravenous or intraductal contrast agent is not necessary due to the typically saliva-filled, prestenotically dilated duct system. However, the poststenotic duct segments can only be insufficiently evaluated due to a lack of saliva. Even if MR sialography is inferior to conventional X-ray sialography for the visualization of the smallest branches of the duct system, it provides superior visualization of the duct system in relation to periductal soft tissue structures and can be performed in a pain-free manner ( $\bullet$ Fig. 2 ). The spatial resolution MR sialography is inferior to that of sialendoscopy and the differentiation between concretions, mucus obstructions, and polyps is also complicated by comparable MR signaling of different pathological processes [8]. However, artificial dilation of the duct system for example due to application of endoscopic equipment, lavage, or contrast agent application does not occur. There is no potentially painful external compression as in sonography. 


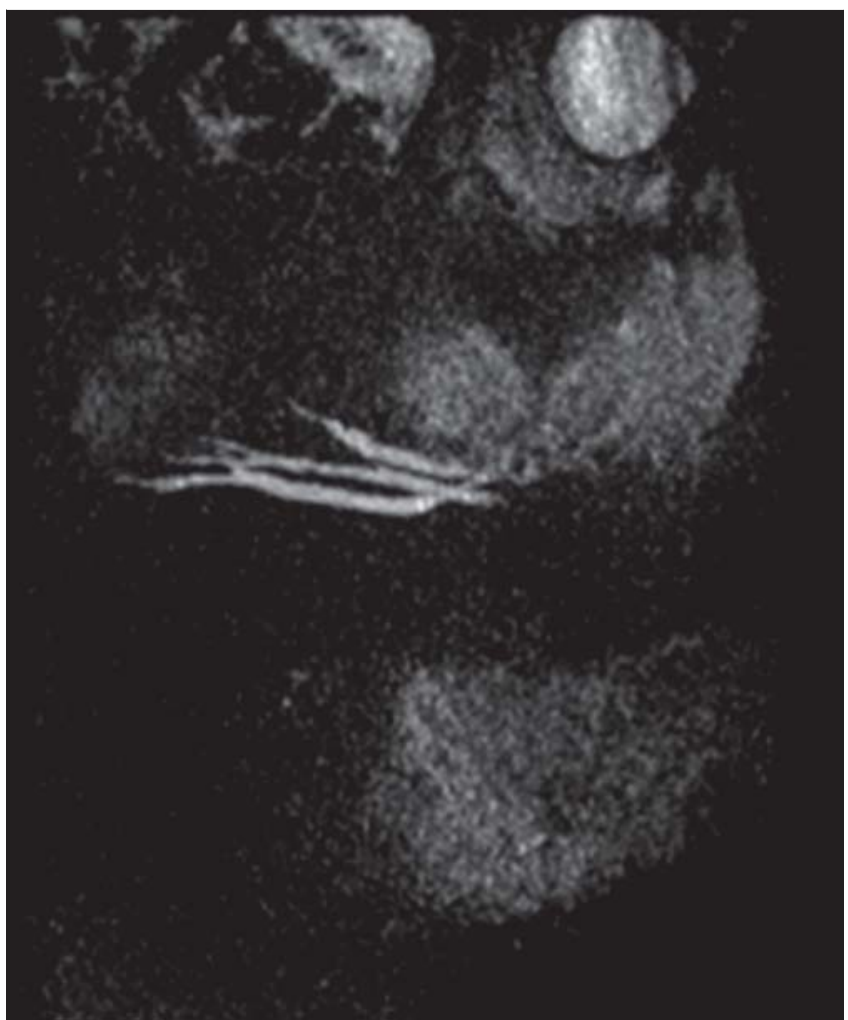

Fig. 1 The MIP reconstruction of strong T2-weighted sequences allows illustration of the excretory duct: 36-year-old patient with a widened tripartite parotid duct due to distal stenosis

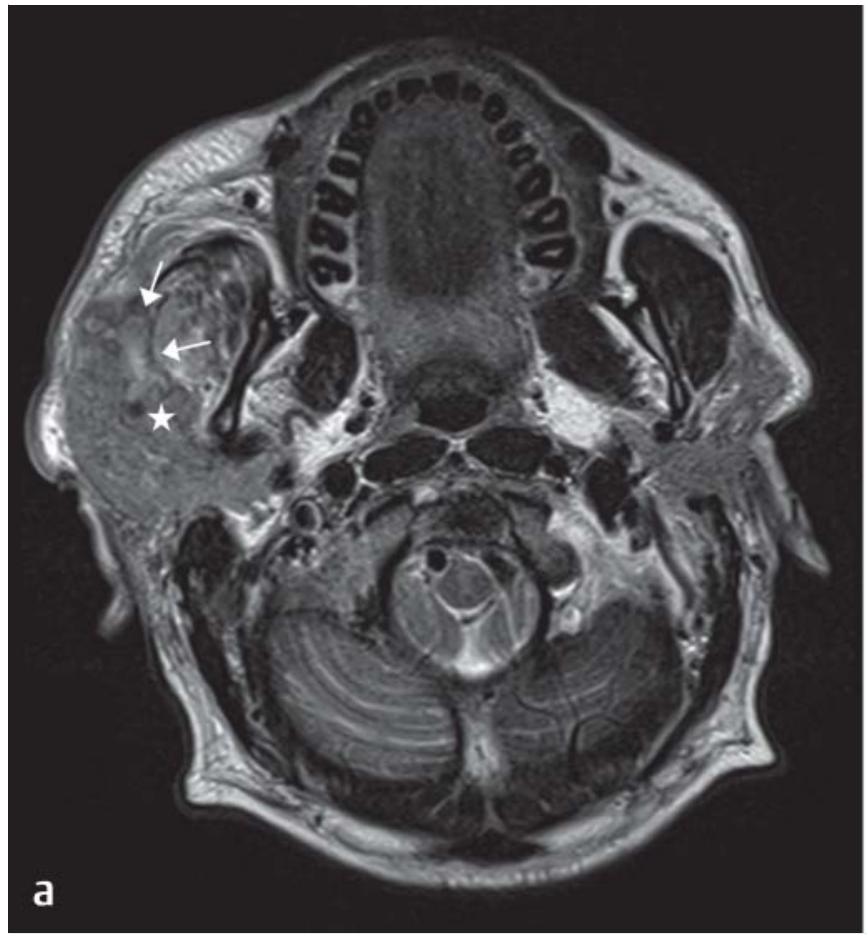

Fig. 2 a 60-year-old patient with obstructive sialadenitis of the right parotid gland. The concrement can be seen in the proximal duct with its typical signal loss $\left({ }^{*}\right)$ and dilation of the upstream duct $(\rightarrow)$, which is already visible in the native T2w sequence. $\mathbf{b}$ After contrast application, the typical unilat-

\section{Conventional X-ray/DSA sialography}

The formerly widely used conventional X-ray and DSA sialography has been increasingly replaced by radiation-free methods such as MR sialography or sialendoscopy performed with an interventional intention. Contrast agent is applied to the Wharton's duct or parotid duct in a retrograde manner with a contrast defect or contrast stoppage indirectly indicating the presence of an obstruction. The method has high sensitivity and allows excellent evaluation and measurement of the distal duct system which is helpful for the estimation of the probability of success of an intraductal treatment method (e.g. stone extraction). Salivary stones and duct stenoses can also be treated with a success rate of $80 \%$ as a direct part of conventional X-ray sialography or fluoroscopy [9]. However, inflammation of the duct system cannot be detected with this method [10].

A shared disadvantage with sialendoscopy is the usually painful and time-intensive cannulation, particularly in the case of small-lumen Wharton's ducts, the artificial dilation of the duct systems, and the relative contraindication for being performed in the acute inflammation phase.

\section{Further procedures}

The indication for additional imaging methods is limited as a result of the superficial position of large salivary glands, the ability to effectively evaluate glands and ducts with sonography, the possibility to perform MR sialography without the use of a contrast agent and in a pain-free manner, and the availability of sialendoscopy with an intervention option. Any necessary visualization of filiform duct segments can be performed via conventional X-ray sialography

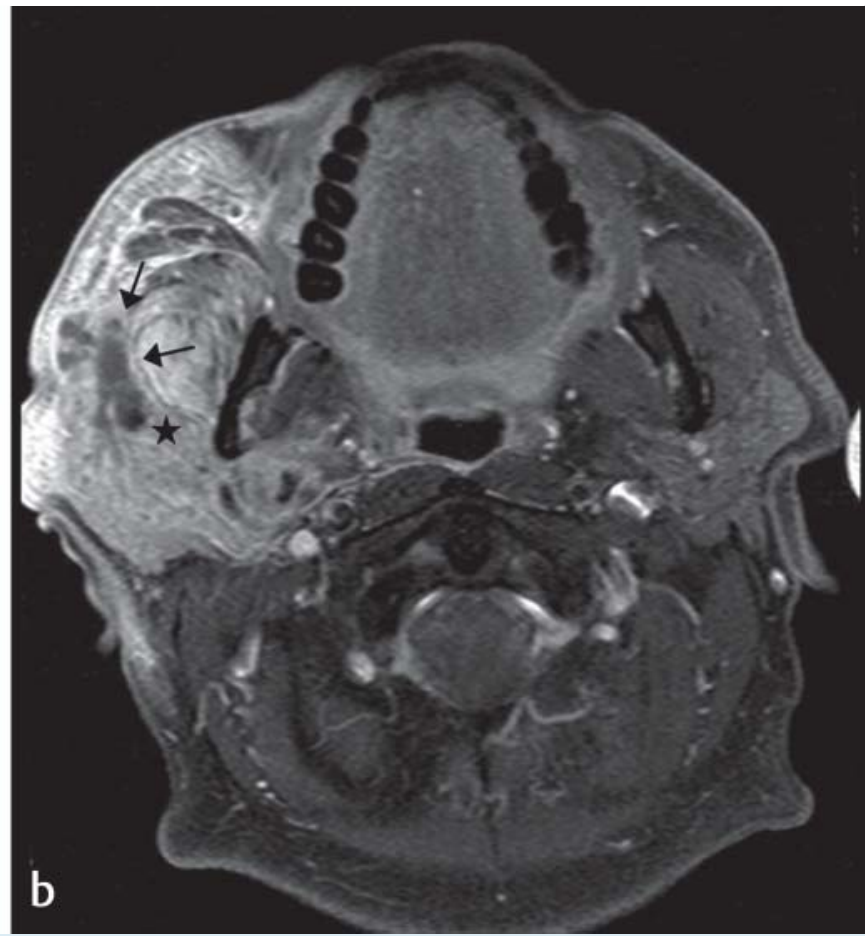

eral enhancement of the inflamed glandular parenchyma and in this case even an inflammatory infiltration of the right infratemporal fossa and the masticatory space can be documented. 


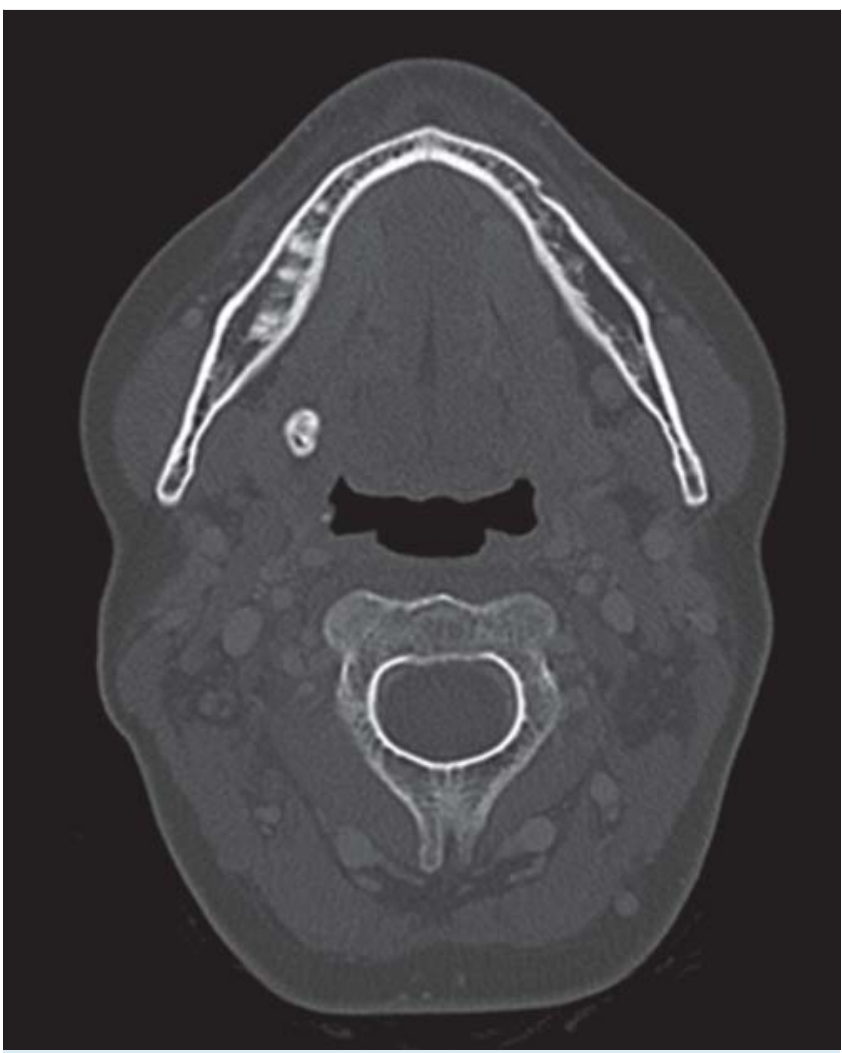

Fig. 3 For detecting especially small concrements, CT imaging is superior to MR imaging. Here a large submandibular concrement is visible.

with acceptance of the radiation exposure. CT or MRI imaging is used for determining infiltration depth in the case of neoplasias. Concretions can be delimited in particular with radiation-based methods, while MRI is the most reliable method for detecting soft tissue changes ( $\bullet$ Fig. 3 ).

The rarely indicated scintigraphy with Tc-99 pertechnetate is available as a functional imaging method which provides very good assessability of salivary gland functioning but has only limited morphological significance [11]. It is not used in cases of acute obstructive sialadenitis but rather in posttherapeutic situations, for example after the treatment of obstructive sialadenitis, external radiation, or radiotherapy [12].

\section{Affiliations}

1 Department of Diagnostic and Interventional Radiology, University Hospital of Frankfurt

2 Department of Oral and Maxillofacial Surgery, University Medicine Mainz

3 Department of Otolaryngology, University Hospital of Cologne

4 Department of Otolaryngology, Hospitals of Cologne

${ }^{5}$ Department of Otolaryngology, University Hospital of Jena

6 Department of Oral, Maxillar and Plastic Surgery, University Hospital of Düsseldorf

7 Department of Oral, Maxillofacial and Plastic Surgery, University Hospital of Bonn

8 Department of Otolaryngology, University Hospital of Schleswig-Holstein, Campus Lübeck

${ }^{9}$ Clinic for Otolarnygology, University Hospital of Gießen/Marburg, Gießen

10 Otolaryngology, Center for Otolaryngology Regensburg

11 Clinic for Otolaryngology, Hospital of Augsburg

\section{References}

1 Iro PDH, Zenk J, Koch M. Moderne Konzepte zur Diagnostik und Therapie der Sialolithiasis. HNO 2010; 58: 211-217

2 Nahlieli O, Baruchin AM. Long-term experience with endoscopic diagnosis and treatment of salivary gland inflammatory diseases. The Laryngoscope 2000; 110: 988 -993

3 Al-Nawas B, Beutner D, Geisthoff $U$ et al. The new S2k AWMF guideline for the treatment of obstructive sialadenitis in commented short form. Laryngorhinootologie 2014; 93: 87-94

4 Marchal F, Chossegros C, Faure F et al. Salivary stones and stenosis. A comprehensive classification. Rev Stomatol Chir Maxillofac 2008; 109: $233-236$

5 ZenkJ, Constantinidis J, Kydles $S$ et al. Clinical and diagnostic findings of sialolithiasis. HNO 1999; 47: 963 -969

6 Zenk J, Iro H, Klintworth $\mathrm{N}$ et al. Diagnostic imaging in sialadenitis. Oral Maxillofac Surg Clin N Am 2009; 21: 275-292

7 Bozzato A, Hertel V, Koch $M$ et al. Vitamin C als Kontrastverstärker bei der sonografischen Diagnostik der obstruktiven Speicheldrüsenerkrankungen. Laryngorhinootologie 2009; 88: 290-292

8 Becker M, Marchal F, Becker CD et al. Sialolithiasis and salivary ductal stenosis: diagnostic accuracy of MR sialography with a three-dimensional extended-phase conjugate-symmetry rapid spin-echo sequence. Radiology 2000; 217: 347-358

9 Koch M, Zenk J, Iro H. Algorithms for treatment of salivary gland obstructions. Otolaryngol Clin North Am 2009; 42: 1173-1192

10 Koch M, Iro H, Zenk J. Stenosen und andere nicht steinbedingte Obstruktionen der Speicheldrüsenausführungsgänge: Moderne Therapiekonzepte. HNO 2010; 58: 218 - 224

11 Bohuslavizki KH, Brenner W, Klutmann S et al. Durchführung und Indikationen der quantitativen Sialoszintigraphie. Laryngo-Rhino-Otol 2008; 76: 614-624

12 Raza $H$, Khan AU, Hameed A et al. Quantitative evaluation of salivary gland dysfunction after radioiodine therapy using salivary gland scintigraphy. Nucl Med Commun 2006; 27: 495 - 499 